\title{
The Knowledge and Attitude about Diarrhea of Mothers of Students Attending an Elementary School in a Suburban Area in Istanbul
}

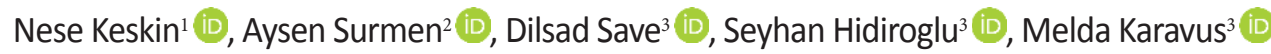 \\ ${ }^{1}$ Ministry of Health, Nigde Community Health Center, Nigde, Turkey. \\ ${ }^{2}$ Ministry of Health, Yozgat Provincial Directorate of Health, Yozgat, Turkey. \\ ${ }^{3}$ Marmara University, School of Medicine, Department of Public Health, Istanbul, Turkey. \\ Correspondence Author: Nese Keskin \\ E-mail: drnsyks@gmail.com \\ Received: 10.01.2018 Accepted: 18.05.2018
}

\section{ABSTRACT}

Objective: Diarrhea is one of the main cause of morbidity and mortality among children age under 5 years in Turkey though diarrheal disease control program has been performing and death ratio due to diarrheal disease under 5 years has been decreasing year by year in Turkey. This study is undertaken to evaluate knowledge, attitude and practice of mothers about childhood diarrheal diseases in a suburban area.

Methods: This descriptive study was carried out in a primary school in a suburban area of istanbul. One hundred and forty four mothers of children included accepted in the study with response rate of $85 \%$. A questionnaire form was applied for data collection. Epi-Info programme was used for statistical analysis. In addition to the descriptive statistical methods, for the comparison of qualitative data a chi-square test was used .

Results: In our study, the percentage of mothers who could define diarrhea correctly was $40 \%$. Abdominal pain and watery defecation were the main signs which the mothers understand their children have diarrhea. Most of the mothers indicated that microbes as the cause of diarrhea. One of every two mothers stated that they would take their children to the doctor as they notice their child has diarrhea. Among the homemade treatments we asked, Potatoes cooked in boiling water and banana were the most frequent answers. Only one of mothers mentioned about using drugs at home for diarrhea and percentage of hearing about ORS was $21.5 \%$. Eleven percent of mothers mentioned they believed to decrease liquid intake would be an effective practice in the treatment of diarrhea. Education level was very influential about knowledge and attitude about diarrheal disease.

Conclusion: This study reveals the importance of continuous health education of mothers as well as the need for raising their status especially schooling in communities. Circulating of correct information is also important as well as educating population.

Keywords: Childhood diarrhea, Mother, Knowledge, Istanbul, Turkey

\section{INTRODUCTION}

Diarrhea is defined as the passage of three or more loose or liquid stools per day (or more frequent passage than is normal for the individual) (1). The incidence of diarrheal diseases varies with the seasons and child's age. As the age is increased, vulnerability is decreased. Incidence is highest in the first two years of life and declines as a child grows (2).

Diarrheal disease is one of the leading causes of mortality and morbidity particularly in developing world. Diarrhea is one of the main cause of morbidity and mortality among children age under 5 years in Turkey though diarrheal disease control program has been performing and death ratio due to diarrheal disease under 5 years has been decreasing year by year in Turkey (3-5). In many developing countries, most diarrhoeal episodes are treated at home, and mothers are the key caregivers to under-five children. They are the ones who decide about the type of food given to the child and the overall management of the disease. Therefore, their knowledge about this common disease is critically important. Awareness of and perception towards diarrhoea, and individual as well as household actions to prevent and/or manage the disease, have paramount importance to reduce diarrhoea-related morbidities and mortalities $(6,7)$.
This descriptive study is undertaken to evaluate knowledge, attitude and practice of mothers about childhood diarrheal diseases in a suburban area. This study will provide information about diarrhea and also provide insight about maternal role and role of the health workers on control of diarrhea. The knowledge about diarrheal disease may contribute to health care provider to empathize with mothers' point of view and dealing with the situation more effectively. Also there is limited number of studies about this topic in Turkey $(8,9)$ and our study will contribute to this literature gap.

\section{METHODS}

This descriptive study was carried out in a primary school in a suburban area of İstanbul. Due to this school is in the education district of medical faculty and relevant for our study, we selected this school. Convenient sampling method was used. Total number of students who had been attended in this school was 420 . We invited 170 mothers of students to participate in our study and 144 of these mothers accepted to participate in the study. Response rate was $85 \%$. Mothers of children were invited to the school for interview. The questionnaires formed by examining related literature were 
applied by the sixth year students of medical faculty who were trained by the researchers to standardize the data collection. Ethics committee permit and institute permit were obtained to perform our research.

\subsection{Statistical Analysis}

Epi-Info programme was used for statistical analysis. In addition to the descriptive statistical methods (mean, standard deviation, and frequency) for the comparison of qualitative data a chi-square test was used. Outcomes were analyzed within $95 \%$ confidence intervals with a significance level of $p<0.05$.

\section{RESULTS}

The mean of mothers' age was 33.2 \pm 5.9 with range of 22-55. The mothers' educational level was poor, $11.8 \%$ illiterate, 3.5 $\%$ literate, $37.5 \%$ of them being elementary school graduates, $15.3 \%$ secondary school graduates and $19.4 \%$ is high school graduates.

Mothers responded the question of "What does diarrhea mean?" in the following way. The percentage of mothers who could give the definition as " watery defecation more than 3 times a day" was $40 \%$ (Table 1 ). Abdominal pain (60.4\%) and watery defecation ( $59.0 \%$ ) were the main signs which the mothers understand their children have diarrhea.

Table 1. Distribution of the Responses of the Mothers to the Question of "What Does Diarrhea Mean?"

\begin{tabular}{|l|l|l|}
\hline Diarrhea definition & $\mathbf{n}$ & $\mathbf{( \% )}$ \\
\hline Watery defecation more than 3 times a day & 54 & 40.0 \\
\hline More than 5 defecation & 49 & 36.3 \\
\hline I don't know & 29 & 21.5 \\
\hline Bloody defecation & 3 & 2.2 \\
\hline Total & 135 & 100.0 \\
\hline
\end{tabular}

Most of the mothers indicated that microbes as the cause of diarrhea. "Cold" was expressed as a cause by $42.4 \%$ of mothers (Table 2).

Table 2. Distribution of the Responses of the Mothers the Question of "What Causes Diarrhea?"

\begin{tabular}{|l|l|l|}
\hline Responses* & $\mathbf{n = 1 4 4}$ & $(\%)$ \\
\hline Microbes & 112 & 77.8 \\
\hline Drinking dirty water & 63 & 43.8 \\
\hline Cold & 61 & 42.4 \\
\hline Dirty and spoiled foods & 46 & 31.9 \\
\hline Antibiotic use & 36 & 25.0 \\
\hline I don't know & 12 & 8.3 \\
\hline Other ** & 10 & 6.9 \\
\hline Other diseases & 9 & 6.3 \\
\hline
\end{tabular}

* more than one answer could be chosen, ** worsening of immune system, emerging teeth, eating from market, dirty toilet, fatty foods, hot weather

One of every two mothers stated that they would take their children to the doctor as they notice their child has diarrhea; $42.8 \%$ of the mothers expressed that they would give some kind of foods to their children at home. Among the homemade treatments we asked, Potatoes cooked in boiling water $(86.1 \%)$ and banana $(79.2 \%)$ were the most frequent answers. Leblebi, rice cooked in boiling water, Salty ayran, Peach, Cola - aspirin, Coffee-lemon, warm water with honey, boiled egg, apple, coffee-yoghurt, lime, maya-water were the other choices for diarrhea used by mothers (Table 3). Only one of mothers mentioned about using drugs at home for diarrhea and percentage of hearing about ORS was $21.5 \%$.

Table 3. Distribution of the Responses of the Mothers to the Question of "How Do You Feed a Child with Diarrhea"

\begin{tabular}{|l|l|l|}
\hline Nutrition in Diarrhea & $\mathbf{n = 1 4 4}$ & $\mathbf{( \% )}$ \\
\hline Potatoes cooked in boiling water & 124 & 86.1 \\
\hline Banana & 114 & 79.2 \\
\hline Roasted chickpeas & 51 & 35.4 \\
\hline Rice cooked in boiling water & 47 & 32.6 \\
\hline Salty ayran & 29 & 20.1 \\
\hline Peach & 22 & 15.3 \\
\hline Cola - aspirin & 22 & 15.3 \\
\hline Coffee-lemon & 21 & 14.6 \\
\hline Other * & 18 & 12.5 \\
\hline Carrot juice & 9 & 6.3 \\
\hline
\end{tabular}

* warm water with honey, boiled egg, apple, coffee-yoghurt, lime, mayawater

More than half of the mothers $(65.7 \%)$ indicated the necessity of more liquid food, but there were still mothers who believed to decrease liquid intake would be an effective practice in the treatment of diarrhea (11.1\%) (Table 4).

Table 4. Distribution of the Responses of the Mothers to the Question of "How Do You Feed Your Children While He Has Diarrhea?"

\begin{tabular}{|l|l|l|}
\hline Responses & $\mathbf{n = 1 4 4}$ & (\%) \\
\hline I give more liquid food & 94 & 65.7 \\
\hline I give more solid food & 59 & 41.0 \\
\hline I give less liquid food & 16 & 11.2 \\
\hline I feed as usual & 18 & 12.5 \\
\hline Other* & 7 & 4.8 \\
\hline
\end{tabular}

* I feed less fatty foods, I give fruits, I feed according to my doctor's recommendations

Education level was very influential about knowledge and attitude about diarrheal disease. While almost half of the mothers graduated from elementary school and above $(44.7$ $\%$ ) could define the diarrhea as 'Watery defecation more than 3 times a day', these knowledge level was $15.0 \%$ among the mothers not literate or literate (Table 5). Also the percentage of the mothers who graduated from at least elementary school $(72.7 \%)$ differed from the mothers who had not graduated from any school $(28.6 \%)$ regarding to giving more liquid food as their children has diarrhea (Table 6). 
Table 5. Relation Between the Mothers' Educational Level and Knowledge about Diarrhea Definition

\begin{tabular}{|c|c|c|c|c|c|c|c|c|c|c|}
\hline \multirow{3}{*}{$\begin{array}{l}\text { Mothers' } \\
\text { Educational } \\
\text { Level }\end{array}$} & \multicolumn{10}{|c|}{ Knowledge about diarrhea definition } \\
\hline & \multicolumn{2}{|c|}{$\begin{array}{l}\text { I don't } \\
\text { know }\end{array}$} & \multicolumn{2}{|c|}{$\begin{array}{c}\text { Watery } \\
\text { defecation } \\
\text { more than } \\
3 \text { times a } \\
\text { day }\end{array}$} & \multicolumn{2}{|c|}{$\begin{array}{c}\text { Watery } \\
\text { defecation } \\
\text { more than } \\
5 \text { times }\end{array}$} & \multicolumn{2}{|c|}{$\begin{array}{c}\text { Bloody } \\
\text { defecation }\end{array}$} & \multicolumn{2}{|c|}{ Total } \\
\hline & $\mathrm{n}$ & $\%$ & $\mathrm{n}$ & $\%$ & $\mathrm{n}$ & $\%$ & $\mathrm{n}$ & $\%$ & $n$ & $\%$ \\
\hline $\begin{array}{l}\text { Literate or } \\
\text { illiterate }\end{array}$ & 11 & 55.0 & 3 & 15.0 & 5 & 25.0 & 1 & 5.0 & 20 & 100.0 \\
\hline $\begin{array}{l}\text { Graduated } \\
\text { from at least } \\
\text { elementary } \\
\text { school }\end{array}$ & 17 & 14.9 & 51 & 44.7 & 44 & 38.6 & 2 & 1.8 & 114 & 100.0 \\
\hline Total & 28 & 20.9 & 54 & 40.3 & 49 & 26.6 & 3 & 2.2 & 134 & 100.0 \\
\hline
\end{tabular}

$p<0.001$, chi-square $=18.480$

Table 6. Relation Between The Mothers' Educational Level and Feeding Their Children with More Liquid Food When They Have Diarrhea

\begin{tabular}{|c|c|c|c|c|c|c|}
\hline \multirow{3}{*}{$\begin{array}{l}\text { Mothers' Educational } \\
\text { Level }\end{array}$} & \multicolumn{4}{|c|}{$\begin{array}{l}\text { Feeding their children with } \\
\text { more liquid food when they } \\
\text { have diarrhea }\end{array}$} & \multirow{2}{*}{\multicolumn{2}{|c|}{ Total }} \\
\hline & \multicolumn{2}{|c|}{ Yes } & \multicolumn{2}{|c|}{ No } & & \\
\hline & $n$ & $\%$ & $n$ & $\%$ & $\mathrm{n}$ & $\%$ \\
\hline Literate or illiterate & 6 & 28.6 & 15 & 71.4 & 21 & 100.0 \\
\hline $\begin{array}{l}\text { Graduated from at least } \\
\text { elementary school }\end{array}$ & 88 & 72.7 & 33 & 27.3 & 121 & 100.0 \\
\hline Total & 94 & 66.2 & 48 & 33.8 & 142 & 100.0 \\
\hline
\end{tabular}

$p<0.001$, chi-square $=15.592, O R=0.15(95 \% \mathrm{Cl}=0.054-0.419)$

\section{DISCUSSION}

Participant mothers' educational level was poor. Percentage of mothers defining diarrhea correctly was $40 \%$ and most of them was higher educational level. Most of the mothers indicated that microbes as the cause of diarrhea. Mothers prefered solid foods such as boiled potatoes (86.1\%) and banana (79.2\%) for their children with diarrhea. More than half of the mothers $(65.7 \%)$ indicated the necessity of more liquid feeding food and this attitude was also highly related with higher educational level. Most of mothers had not heard about ORS.

Despite the negative consequences of illness not only sanitary but also economically and the considerable therapeutic benefits of ORS, application in developing countries has been remaining so low and nonly $43.0 \%$ of children under five in the 'least developed countries' are receiving ORS for the treatment of diarrhea (10). Since 1980's World Health Organization and UNICEF have been issuing the program named Early Treatment of Diarrhea but unfortunately diarrhea is still a leading health problem for children. Insufficient and inaccurate knowledge about diarrhea is still affecting the appropriate attitude in preventing and treatment of diarrhea. In our study, we too found that there are still wrong practices and believes about treatment of diarrhea in communities.

In spite of continuous effort for public education especially in primary health care services, in this study it is found that knowledge about diarrhea such as hearing about ORS $(22,6 \%)$, giving more liquid food (65.7\%), defining diarrhea correctly (40.0\%) is so deficient. Results of a research reported from Turkey indicated that $40.2 \%$ of mothers heard about ORS (9) but asking about ORS usage represented lower rate (6.6\%) in another study from our country (8) and percentage of giving more water was almost the same to our study result (65.2\%). Also many mother (84.4\%) mentioned that they continued breast feeding during diarrhea of children (8). The knowledge that breastfeeding should be continued during diarrhea was only $47.0 \%$ in an interventional study performed in Delhi. But, it is promising to see this percentage increased to $90.0 \%$ after intervention for further interventional studies that can be planned in our country (11).

It is also observed that mothers of the children with diarrhea give more fluids in a considerable percentage (65.7\%), but still there are mothers who make no changes in the fluid intake of their children with diarrhea (12.6\%), and who decrease the fluid intake (11.2\%).

It is revealed that educational level plays an important role in deciding to take the child having diarrhea to a doctor. Although in our study mothers having higher education (high school, university graduates) were not represented, graduates of primary school were found to have a considerable important impact on mothers' attitude towards usage of health care facilities. This effect may be attributed to defining role of education of mothers, women's status in communities and mothers' freedom to get into contact with the outdoor environments.

In a study carried out in Belgium majority of mothers were found to prefer home available fluids (78.7\%) and $81.0 \%$ of the mother who attended our study also prefer giving different types of treatments to their children at home. There are many types of traditional feeding practices in Anatolia to treat the child at home, such as bitter, well steeped tea, well steeped tea with pepper, raw onion, lemon salt, banana, salty ayran, kola, boiled potatoes, leblebi, wheat in oil, to keep the child warm etc (12). Especially rice boiled in water is one of the classical menu for diarrheal diseases in the Turkish culture. Ulaş et al. reported that besides more liquid and breast feeding, boiled potatoes (87.6\%) and rice (62.6\%) were most preferred solid foods for feeding during diarrhea. In our study, potatoes cooked in boiling water (86.1 $\%)$ and banana (79.2 \%) are the most preferred feeding style supporting our cultural practices. Similar to our culture, a study in Kosovo revealed that rice water (19.6\%), bananas (15.9\%), tea (7.5\%), potatoes (6.5\%) are commonly used to treat diarrhea (13).

"Cold" is one of the important causes of many diseases in the Turkish culture. It is shown that acute respiratory disease, urinary diseases, rheumatological diseases and headache 
are thought to be caused by cold in the Turkish culture (12). This study also supported this believe expressing 'Cold' as a cause by $42.7 \%$ of mothers. If the real cause of a disease is not known, preventive measures as well as the appropriate treatment can't be performed seriously. When the TDHS data is compared between the years 1998 and 2008, slight increase in diarrheal disease frequency is observed (30.0\% to $23.0 \%)$ indicating decrease of the poor sanitation practices and the use of contaminated water supplies. In our study, the mothers expressed that dirty-spoiled foods (32.2\%) and dirty water $(44.1 \%)$ can cause diarrhea and they seemed to be aware of the diarrhea causing effect of unsafe foods and drinks sold in open markets and school canteens. This awareness also exist in Belgaum reported by results that drinking contaminated water $(80.3 \%)$ and eating contaminated food (68.42 \%) expressed as cause of diarrhea (14).

\section{CONCLUSION}

This study reveals the importance of continuous health education of mothers as well as the need for raising their status especially schooling in communities. Circulating of correct information is also important as well as educating population. Eventually planning and performing our study as a descriptive study was a limitation. So that, the results represent the research sample and cannot be generalized for population.

\section{REFERENCES}

[1] World Health Organization. Diarrhoeal disease 2017. Available from: http://www.who.int/mediacentre/factsheets/fs330/en/.

[2] Unicef. Diarrhoea: why children are still dying and what can be done. http://www.unicef org/media/files/Final_Diarrhoea_ Report_October_2009_final pdf. 2010.

[3] Liu L, Johnson HL, Cousens S, Perin J, Scott S, Lawn JE, Rudan I, Campbell H, Cibulskis R, Li M, Mathers C, Black RE. Global, regional, and national causes of child mortality: an updated systematic analysis for 2010 with time trends since 2000 . The Lancet. 2012;379(9832):2151-2161.

[4] Turkey Demographic and Health Survey (TDHS-2013). The Hacettepe University. TR Ministry of Health, Ankara. Available from: http://www. hips. hacettepe. edu. tr/tnsa2003/ anaraporenglish. htm.

[5] Turkish Statistical Institute. Türkiye Sağlık Araştırması, 2016 [August 2017]. Available from: http://www.tuik.gov.tr/ PreHaberBultenleri.do?id=24573.

[6] Merga N, Alemayehu T. Knowledge, perception, and management skills of mothers with under-five children about diarrhoeal disease in indigenous and resettlement communities in Assosa District, Western Ethiopia. J Health Popul Nutr. 2015;33(1):20.

[7] Yilgwan CS, Okolo S. Prevalence of diarrhea disease and risk factors in Jos University Teaching Hospital, Nigeria. Ann Afr Med. 2012;11(4):217.

[8] Şanlıer N, Aytekin F. Sıfır üç yaş grubunda çocuğu bulunan annelerin beslenme ve ishal konusunda bilgi ve davranışlarının incelenmesi. GEFAD.2004;24(3):81-100 (Turkish).

[9] Ulaş SC, Çetinkaya AÇ, Özmen D, Çevik K. 0-6 yaş çocuklarda ishal olmayı etkileyen etmenler ve annelerin ishal konusundaki bilgi düzeyleri. STED. 2012:236 (Turkish).

[10] Unicef. The State of the World's Children 2016:128-129.

[11] Pahwa S, Kumar GT, Toteja G. Performance of a communitybased health and nutrition-education intervention in the management of diarrhoea in a slum of Delhi, India. J Health Popul Nutr. 2010;28(6):553.

[12] Bulut A, Gokçay G, Gökşen F, Gürsor A, Kartoğlu U, Neyzi O. The basics of maternal and child health. Amman: UNICEF; 1994.

[13] Berisha M, Hoxha-Gashi S, Gashi M, Ramadani N. Maternal practice on management of acute diarrhea among children under five years old in Kosova. TAF Prev Med Bull. 2009;8(5):369-372.

[14] Anil M. Knowledge, attitude and practices regarding diarrhoea and its management among mothers of under five children at vantamuri sub centre in belgaum district-a cross sectional study: Kle University, Belgaum, Karnataka, PhD Thesis. 2011. 